\title{
OPEN Whole blood chromium concentration is very rarely elevated independently of whole blood cobalt
}

\author{
Olli Lainiala ${ }^{1,2 \varpi}$, Mari Karsikas ${ }^{1,3}$, Aleksi Reito ${ }^{1,4}$ \& Antti Eskelinen ${ }^{1}$
}

Due to the risk of adverse reactions to metal debris resulting from increased wear of the arthroplasty more than one million metal-on-metal (MoM) hip replacements worldwide are in active follow-up. Follow-up usually includes measurement of both whole blood cobalt (Co) and chromium ( $\mathrm{Cr}$ ) concentrations. Our experience is that $\mathrm{Cr}$ is seldom independently elevated. We wanted to ascertain whether blood $\mathrm{Cr}$ measurements could be omitted from follow-up protocols without lowering the quality of follow-up. We identified 8438 whole blood $\mathrm{Co}$ and $\mathrm{Cr}$ measurements performed without or prior to revision surgery. When the cut-off levels $5 \mu \mathrm{g} / \mathrm{L}$ and $7 \mu \mathrm{g} / \mathrm{L}$ were used, $\mathrm{Cr}$ was independently elevated in only $0.5 \%$ ( $95 \%$ confidence interval, $\mathrm{Cl}, 0.3$ to 0.6 ) and $0.2 \%$ ( $\mathrm{Cl} 0.1$ to 0.3 ) of the measurements. The models with continuous variables showed that the higher the blood metal concentrations are the lower the percentage of measurements with $\mathrm{Cr}$ higher than $\mathrm{Co}$. Our results suggest that whole blood $\mathrm{Cr}$ is very rarely independently elevated and therefore the authorities should consider omitting $\mathrm{Cr}$ measurements from their screening guidelines of MoM hip replacements. We believe this change in practice would simplify follow-up and lead to cost savings without decreasing the quality of follow-up.

After the acknowledgement of adverse reactions to metal debris and unacceptably high revision rates among metal-on-metal (MoM) hip replacements a decade ago, several national and international authorities published follow-up guidelines for MoM hip replacements that included clinical evaluation, imaging, and whole blood or serum metal ion measurements ${ }^{1-4}$. In 2012, it was estimated that there were nearly one million MoM hip replacements in the United States (US), and the number was still increasing. In the United Kingdom (UK), the number of MoM hip replacements is around 70,000 , and in Australia it is around 35,000 3 . As an approximation, the figure of 1.5 million MoM hip replacements worldwide is often quoted ${ }^{7}$.

In their latest guidelines, both the UK Medicines and Healthcare products Regulatory Agency (MHRA) ${ }^{8}$ and the Australian Therapeutic Goods Administration (TGA) ${ }^{3}$ recommend the testing of both whole blood cobalt (Co) and chromium (Cr) for all patients with MoM hip replacements. Furthermore, the Scientific Committee on Emerging and Newly Identified Health Risks (SCENIHR) of the European Commission recommends blood metal ion measurements from all patients with a large head size MoM total hip arthroplasty (THA) implant or hip resurfacing ${ }^{4}$. Conversely, the US Food and Drugs Administration (FDA) recommends measuring Co from symptomatic patients, but does not consider the measurement of $\mathrm{Cr}$ a necessity ${ }^{2}$. Moreover, whereas most guidelines recommend annual systematic follow-up for the life of the implant for high risk implant/patient groups $s^{3,4,8,9}$, the FDA does not recommend the metal ion testing of asymptomatic patients with no abnormal clinical or radiographic signs ${ }^{2}$.

The cost of the measurements varies depending on the institution, but the prices mentioned in the literature range, for example, from $\$ 50$ to $\$ 62$ per measurement ${ }^{10,11}$. During the follow-up of patients at our institution, we have noticed that $\mathrm{Cr}$ is seldom higher than Co at concentrations above the suggested cut-off values of $5 \mu \mathrm{g} / \mathrm{L}^{12}$ or $7 \mu \mathrm{g} / \mathrm{L}^{1}$, and even when $\mathrm{Cr}$ is higher, Co is also found to be elevated. Atrey et al. reported that none of their 469 MoM patients had an independently elevated serum $\mathrm{Cr}$ level, and that they have stopped measuring $\mathrm{Cr}$ and now

${ }^{1}$ Coxa Hospital for Joint Replacement and Faculty of Medicine and Health Technologies, Tampere University, Niveltie 4, 33520 Tampere, Finland. 'Imaging Centre, Department of Radiology, Tampere University Hospital, Kuntokatu 2, 33520 Tampere, Finland. ${ }^{3}$ Center for Life Course Health Research, University of Oulu, P.O.Box 8000, 90014 Oulu, Finland. 'Department of Orthopaedics and Traumatology, Tampere University Hospital, Kuntokatu 2, 33520 Tampere, Finland. ${ }^{\bowtie}$ email: olli.lainiala@tuni.fi 
only measure Co which saves $\$ 18$ per measurement ${ }^{10}$. Also Matharu et al. suggested that measuring Co only is sufficient and with their laboratory prices the saving per measurement is $\$ 15.40^{13}$.

We conducted a study to analyze whether $\mathrm{Cr}$ measurements are needed, or whether standard follow-up protocols could be run by only including blood Co measurements. The aims of the study were to answer the following questions: 1) What percentage of whole blood Co and Cr measurements have higher Cr than Co and 2) In how many measurements is $\mathrm{Cr}$ independently elevated when the cut-off values of $5 \mu \mathrm{g} / \mathrm{L}$ or $7 \mu \mathrm{g} / \mathrm{L}$ are used?

\section{Materials and methods}

The study was approved by the Tampere University Hospital Ethics Committee (approval ID R11006 and R11196). Based on Data Protection Act in Finland, informed consent was not needed in this study because only retrospective analysis of the data collected during standard care was performed and this study did not include any additional contacts or tests on the patients. The need for informed consent was waived by the Tampere University Hospital Ethics Committee. The ethical guidelines of the World Medical Association's Declaration of Helsinki were followed.

After the recall of the Articular Surface Replacement (ASR, Depuy Orthopaedics, Warsaw, IN) ${ }^{14}$ and reports of its poor survival in the Australian Orthopaedic Association Joint Replacement Registry ${ }^{15}$, our institution launched an intensified screening program for all ASR MoM hip replacements in 2010. Screening included whole blood $\mathrm{Co}$ and $\mathrm{Cr}$ measurements, physical examination, and cross-sectional imaging with magnetic resonance imaging as the primary imaging modality. Later, in 2012, other MoM hip replacement brands were also included in the screening program.

Blood samples were drawn from the antecubital vein with a vacutainer system. The first $10 \mathrm{~mL}$ was used for other analyses to prevent Co and Cr contamination from the needle. Whole blood Co and Cr measurements were performed with dynamic reaction cell inductively coupled plasma mass spectrometry (Agilent $7500 \mathrm{cx}$ or 8800, Agilent Technologies, Santa Clara, CA, USA).

We included all patients with a MoM hip replacement implanted at our institution. For these patients, all Co and $\mathrm{Cr}$ measurements available in our laboratory database were retrieved. The patients with MoM hip replacements were identified from our hospital database. The data scientist then deidentified the data before continuing to further data retrieval and analyses. No referral patients were included.

Statistics. The percentage of measurements with $\mathrm{Cr}$ higher than Co was calculated. As there are differences in metal ion release from stemmed THAs and hip resurfacings ${ }^{16}$, subgroup analyses were performed for the measurements from patients with stemmed THA (unilateral or bilateral) and for those measurements from patients with hip resurfacing (unilateral or bilateral). Measurements from patients with THA in one hip and resurfacing in the other hip were not analyzed as a separate group. As it has been previously reported that $\mathrm{Cr}$ might remain elevated after revision surgery ${ }^{17}$, measurements performed after revision surgery were excluded from most of our analysis. The analyses without exclusion are shown in Supplement 1. In patients with bilateral MoM hip replacement, the exclusion was done after the first revision, and therefore even if they had one MoM hip replacement remaining, the measurements taken after the revision were omitted. To analyze the percentage of measurements with independently elevated $\mathrm{Cr}$, we reported the number of measurements with $\mathrm{Cr}$ higher than Co in those cases where either Co or Cr exceeded the cut-off value. In the analysis, we used two commonly used cut-off values, $5 \mu \mathrm{g} / \mathrm{L}$ by Hart et al. ${ }^{12}$ and $7 \mu \mathrm{g} / \mathrm{L}$ by the UK MHRA ${ }^{1}$. The Wilson method was used for calculating $95 \%$ confidence intervals (CI).

Because several other cut-off values have been suggested ${ }^{13,18-20}$ and there is no consensus on the best cut-off value or even whether cut-offs values should be used at all, we also analyzed the concentrations as continuous variables. The analysis was performed by ranking the measurements by whole blood Co concentration and plotting the percentage of measurement with Cr higher than Co among the measurements, where Co is above a specified value. Further, Bland-Altman plots were drawn to describe the differences between Co and Cr levels. Plots were drawn separately for all measurements, for measurements from patients with stemmed THA, and for measurements from patients with hip resurfacing. Because our study included repeated measurements from some of the patients, we performed the main analyses with inclusion of only one measurement per patient (most recent measurement before/without revision surgery) as sensitivity analysis and presented them in Supplement 2.

The analyses were performed with $\mathrm{R}$ (Version 3.5.1) ${ }^{21}$.

\section{Results}

At our institution, 2520 patients (3013 hips) were implanted with a MoM hip replacement between November 1999 and February 2012. We identified a total of 10,962 Co-Cr measurements drawn from 2254 patients. Patient demographics are presented in Table 1. Whole blood Co and $\mathrm{Cr}$ measurements were performed between January 2008 and February 2020. The mean time from primary surgery to the whole blood metal ion measurement was 8.3 years (SD 3.4). Of these measurements, 6667 were from patients with unilateral or bilateral THA, 4101 from patients with unilateral or bilateral hip resurfacing, and 194 were from patients with THA in one hip and hip resurfacings in the other. Cr was higher than Co in 4958 (45\%, CI 44-46) of the 10,962 measurements. Among THAs, Cr was higher in 2170 (33\%, CI 31-34) and among hip resurfacings in 2714 (66\%, CI 65-68) (Table 2).

A total of 8438 measurements were performed either prior to revision surgery or on patients who had not undergone revision (2524 measurements after revision). Among these, Cr was higher in 3543 (42\%, CI 41 to 43 ) of the measurements. Cr was higher in 1194 (25\%, CI 24 to 27) of the measurements performed on patients with stemmed THA and in 2322 (66\%, CI 64 to 67$)$ of those with hip resurfacing.

Among the measurements drawn from those who had not undergone revision surgery, either Co or Cr was above the $5 \mu \mathrm{g} / \mathrm{L}$ cut-off ${ }^{12}$ in 2024 (24\%, CI 23 to 25$)$ measurements and above the $7 \mu \mathrm{g} / \mathrm{L}^{1}$ cut-off in $1362(16 \%$, 


\begin{tabular}{|l|l|l|l|}
\hline & All patients with MoM hips & MoM total hip arthroplasty & MoM hip resurfacing \\
\hline No. of patients & 2254 & 1335 & 890 \\
\hline No. of paired measurements & 10,962 & 6667 & 4101 \\
\hline Median Co (range, $\mu \mathrm{g} / \mathrm{L})$ & $1.7(0.1-225)$ & $2.5(0.1-192)$ & $1.2(0.1-225)$ \\
\hline Median Cr $($ range, $\mu \mathrm{g} / \mathrm{L})$ & $1.6(0.1-125)$ & $1.7(0.1-115)$ & $1.4(0.1-125)$ \\
\hline Age at surgery, median $($ range) & $68(16-93)$ & $70(19-93)$ & $63(16-91)$ \\
\hline Gender (female/male, $\mathrm{n}, \%)$ & $1037(46 \%) / 1217(54 \%)$ & $667(50 \%) / 668(50 \%)$ & $347(39 \%) / 543(61 \%)$ \\
\hline
\end{tabular}

Table 1. Demographics of the patients from whom the whole blood cobalt and chromium samples were drawn. MoM, metal-on-metal; Co, cobalt; Cr, chromium.

\begin{tabular}{|c|c|c|c|c|c|c|c|c|c|c|c|c|c|c|}
\hline \multirow[b]{2}{*}{$\begin{array}{l}\text { Type of } \\
\text { implant }\end{array}$} & \multicolumn{3}{|c|}{ Total number of measurements } & \multicolumn{3}{|c|}{$\begin{array}{l}\text { Measurements before or } \\
\text { without revision }\end{array}$} & \multicolumn{4}{|c|}{$\begin{array}{l}\text { Before or without revision and Co or } \\
\mathrm{Cr} \geq 5 \mu \mathrm{g} / \mathrm{L}\end{array}$} & \multicolumn{4}{|c|}{$\begin{array}{l}\text { Before or without revision and Co or } \\
\mathrm{Cr} \geq 7 \mu \mathrm{g} / \mathrm{L}\end{array}$} \\
\hline & $\mathbf{n}$ & $\begin{array}{l}\text { Cr higher } \\
\text { n/\% (CI) }\end{array}$ & $\begin{array}{l}\text { Cr lower } \\
\text { or equal } \\
\text { n/\% (CI) }\end{array}$ & $\mathbf{N}^{*}$ & $\begin{array}{l}\text { Cr higher } \\
\text { n/\% (CI) }\end{array}$ & $\begin{array}{l}\text { Cr lower } \\
\text { or equal } \\
\text { n/\% (CI) }\end{array}$ & $\mathbf{n}$ & $\begin{array}{l}\text { Cr higher } \\
\text { n/\% (CI) }\end{array}$ & $\begin{array}{l}\text { Cr lower } \\
\text { or equal } \\
\text { n/\% (CI) }\end{array}$ & $\begin{array}{l}\mathrm{Cr} \geq 5 \text { and } \\
\mathrm{Co}<5 \\
\mathrm{n} / \% / \% \text { of } \\
\mathrm{N}^{*}(\mathrm{CI})\end{array}$ & $\mathbf{n}$ & $\begin{array}{l}\mathrm{Cr} \\
\text { higher } \\
\text { n/\% } \\
\text { (CI) }\end{array}$ & $\begin{array}{l}\text { Cr lower } \\
\text { or equal } \\
\text { n/\% (CI) }\end{array}$ & $\begin{array}{l}\mathrm{Cr} \geq 7 \text { and } \\
\mathrm{Co}<7 \\
\mathbf{n} / \% / \text { of } \mathrm{N}^{*} \\
(\mathrm{CI})\end{array}$ \\
\hline All & 10,962 & $\begin{array}{l}4958 / \\
45 \% \\
(44-46)\end{array}$ & $\begin{array}{l}6004 / \\
55 \% \\
(54-56)\end{array}$ & 8438 & $\begin{array}{l}3543 / \\
42 \% \\
(41-43)\end{array}$ & $\begin{array}{l}4895 / \\
58 \% \\
(57-59)\end{array}$ & 2024 & $\begin{array}{l}79 / \\
3.9 \% \\
(3.1-4.8)\end{array}$ & $\begin{array}{l}1945 / \\
96 \% \\
(95-97)\end{array}$ & $\begin{array}{l}38 \\
/ 1.9 \% \\
(1.4-2.6) \\
/ 0.5 \% \\
(\mathbf{0 . 3}-\mathbf{0 . 6 )}\end{array}$ & 1362 & $\begin{array}{l}27 / \\
2.0 \% \\
(1.4- \\
2.9)\end{array}$ & $\begin{array}{l}1335 / \\
98 \% \\
(97-99)\end{array}$ & \begin{tabular}{|l|}
13 \\
$/ 1.0 \%$ \\
$(0.6-1.6)$ \\
$/ 0.2 \%$ \\
$(\mathbf{0 . 1}-\mathbf{0 . 3})$
\end{tabular} \\
\hline THA & 6667 & $\begin{array}{l}2170 / \\
33 \% \\
(31-34)\end{array}$ & $\begin{array}{l}4497 / \\
67 \% \\
(66-69)\end{array}$ & 4769 & $\begin{array}{l}1194 / \\
25 \% \\
(24-27)\end{array}$ & $\begin{array}{l}3575 / \\
75 \% \\
(74-76)\end{array}$ & 1712 & $\begin{array}{l}18 / \\
1.1 \% \\
(0.7-1.7)\end{array}$ & $\begin{array}{l}1694 / \\
98.9 \% \\
(98.3-99.3)\end{array}$ & $\begin{array}{l}9 \\
/ 0.5 \% \\
(0.3-1.0) \\
/ 0.2 \% \\
(\mathbf{0 . 1}-\mathbf{0 . 4})\end{array}$ & 1178 & $\begin{array}{l}6 / \\
0.5 \% \\
(0.2- \\
1.1)\end{array}$ & $\begin{array}{l}1172 / \\
99.5 \% \\
(98.9-99.8)\end{array}$ & \begin{tabular}{|l|}
4 \\
$/ 0.3 \%$ \\
$(0.1-0.9)$ \\
$/ \mathbf{0 . 1} \%$ \\
$(\mathbf{0 . 0 3 - 0 . 2 )}$
\end{tabular} \\
\hline $\begin{array}{l}\text { Hip resur- } \\
\text { facing }\end{array}$ & 4101 & $\begin{array}{l}2714 / \\
66 \% \\
(65-68)\end{array}$ & $\begin{array}{l}1387 / \\
34 \% \\
(32-35)\end{array}$ & 3543 & $\begin{array}{l}2322 / \\
66 \% \\
(64-67)\end{array}$ & $\begin{array}{l}1221 / \\
34 \% \\
(33-36)\end{array}$ & 259 & $\begin{array}{l}58 / \\
22 \% \\
(17-28)\end{array}$ & $\begin{array}{l}201 / \\
78 \% \\
(72-82)\end{array}$ & $\begin{array}{l}27 \\
/ 10 \% \\
(7.2-15) \\
/ \mathbf{0 . 8} \% \\
(\mathbf{0 . 5}-\mathbf{1 . 1})\end{array}$ & 145 & $\begin{array}{l}19 / \\
13 \% \\
(8.6- \\
20)\end{array}$ & $\begin{array}{l}126 / \\
87 \% \\
(80-91)\end{array}$ & \begin{tabular}{|l|}
8 \\
$/ 5.5 \%$ \\
$(2.8-11)$ \\
$/ \mathbf{0 . 2 \%}$ \\
$(\mathbf{0 . 1 - 0 . 5 )}$
\end{tabular} \\
\hline
\end{tabular}

Table 2. Percentages of paired measurements with higher whole blood chromium value compared to cobalt. Co, cobalt; Cr, chromium; CI, 95\% confidence interval; THA, total hip arthroplasty. In columns "measurements before or without revision" the Co and Cr measurements performed after a revision surgery are excluded because it is known that whole blood Cr may remain elevated longer than Co after revision surgery ${ }^{17}$.

CI 15 to 17) measurements. Cr was higher than Co in 79 (3.9\%, CI 3.1 to 4.8$)$ of the measurements, where Co or Cr was above $5 \mu \mathrm{g} / \mathrm{L}$ and in 27 (2.0\%, CI 1.4 to 2.9), where Co or Cr was above $7 \mu \mathrm{g} / \mathrm{L}$. Independently elevated Cr values (Cr above the cut-off and Co below the cut-off) were seen in 38 (0.5\%, CI 0.3 to $0.6,5 \mu \mathrm{g} / \mathrm{L}$ cut-off) or $13(0.2 \%$, CI 0.1 to $0.3,7 \mu \mathrm{g} / \mathrm{L}$ cut-off) of the 8438 measurements (Table 2$)$. The same analyses without the exclusion of the measurements after revision surgery resulted in higher percentage of Cr being independently elevated (Supplement 1).

The very small percentage of the measurements with $\mathrm{Cr}$ higher than Co at higher whole blood Co concentrations is presented in Fig. 1. Bland-Altman plots for all measurements (Fig. 2), measurements from THAs (Fig. 3), and from hip resurfacings (Fig. 4) also demonstrate that measurements with Cr higher than Co are only seen at relatively low values. At very high concentrations, there are virtually no measurements where $\mathrm{Cr}$ is higher than Co. Sensitivity analyses performed with inclusion of only one measurement per patient resulted in an even smaller percentage of independently elevated whole blood $\mathrm{Cr}$ (Supplement 2 and 3).

\section{Discussion}

The results of our study show that at whole blood Co and $\mathrm{Cr}$ concentrations above the cut-offs of $5 \mu \mathrm{g} / \mathrm{L}$ and $7 \mu \mathrm{g} / \mathrm{L}, \mathrm{Cr}$ measurements add very little to Co measurements in detecting high wearing MoM hip replacements. At lower levels, there are more measurements where $\mathrm{Cr}$ is higher than $\mathrm{Co}$, but we do not consider these to be relevant. The median whole blood $\mathrm{Cr} 1.5 \mu \mathrm{g} / \mathrm{L}$ and $\mathrm{Co} 0.5 \mu \mathrm{g} / \mathrm{L}$ have been reported as background concentrations analyzed from 3042 blood samples donated to a local transfusion center ${ }^{20}$. We believe that in asymptomatic patients with no evidence of osteolysis, loosening, or fractures in x-ray, only slightly (independently) elevated $\mathrm{Cr}$ would not lead to revision at virtually any institution.

To the best of our knowledge, this is the largest number of Co-Cr measurements published to date from a single institution. The strength of our study is the unselected patient group. Our hospital is a large primary center, with a high volume of approximately 2000 primary hip arthroplasties per year, performing more than $95 \%$ of the hip arthroplasties in our region. Our public health care system ensures that this patient group represents the overall MoM population in terms of gender, age, socioeconomic status, and lifestyle. From the implant brand 


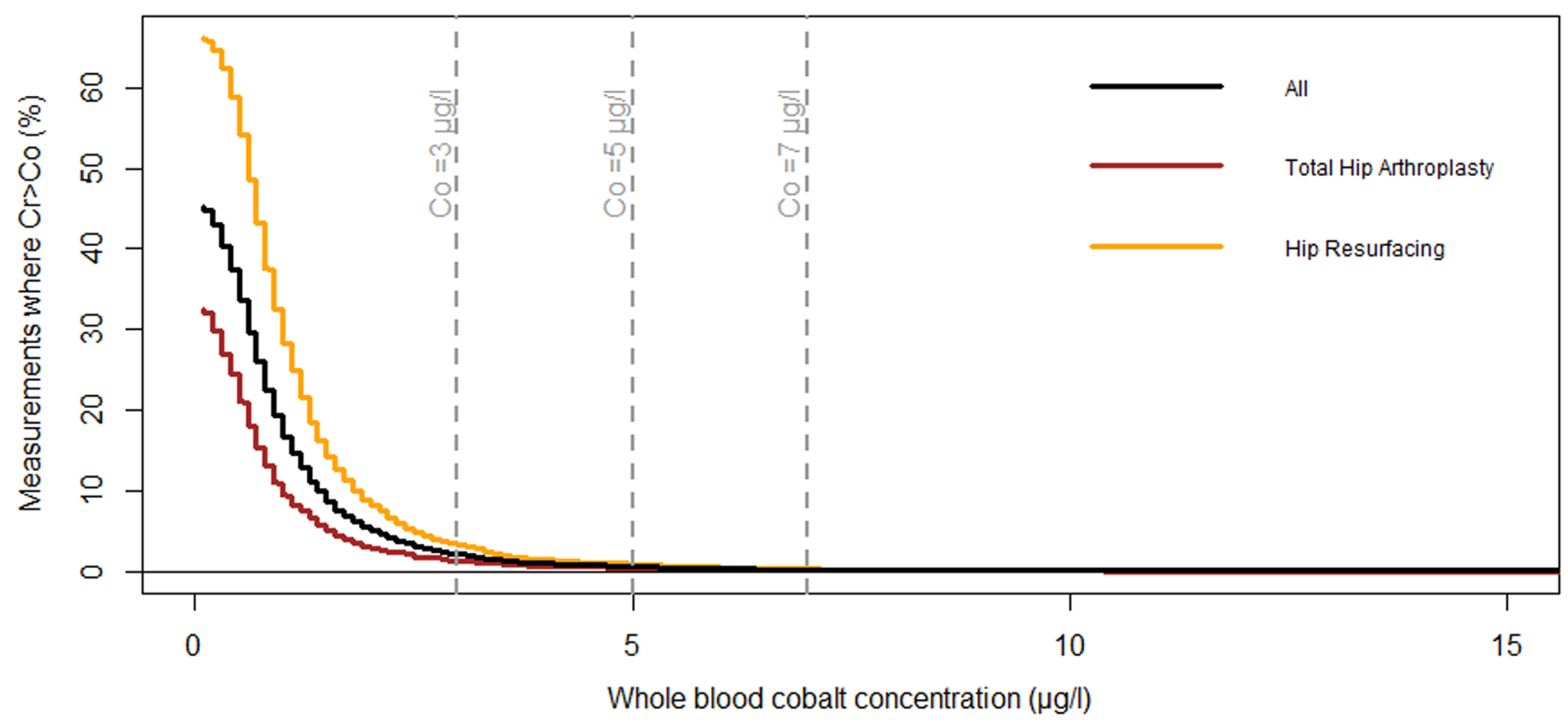

Figure 1. The relationship between whole blood cobalt (Co) concentration and the percentage of measurements where chromium $(\mathrm{Cr})$ concentration is higher than Co. At a certain whole blood Co value, the curve tells us what percentage of the measurements with Co above the value have higher whole blood $\mathrm{Cr}$ than Co. "All" corresponds to all measurements performed without or before revision surgery. Figure drawn with $\mathrm{R}$ (Version 3.5.1) $)^{21}$.

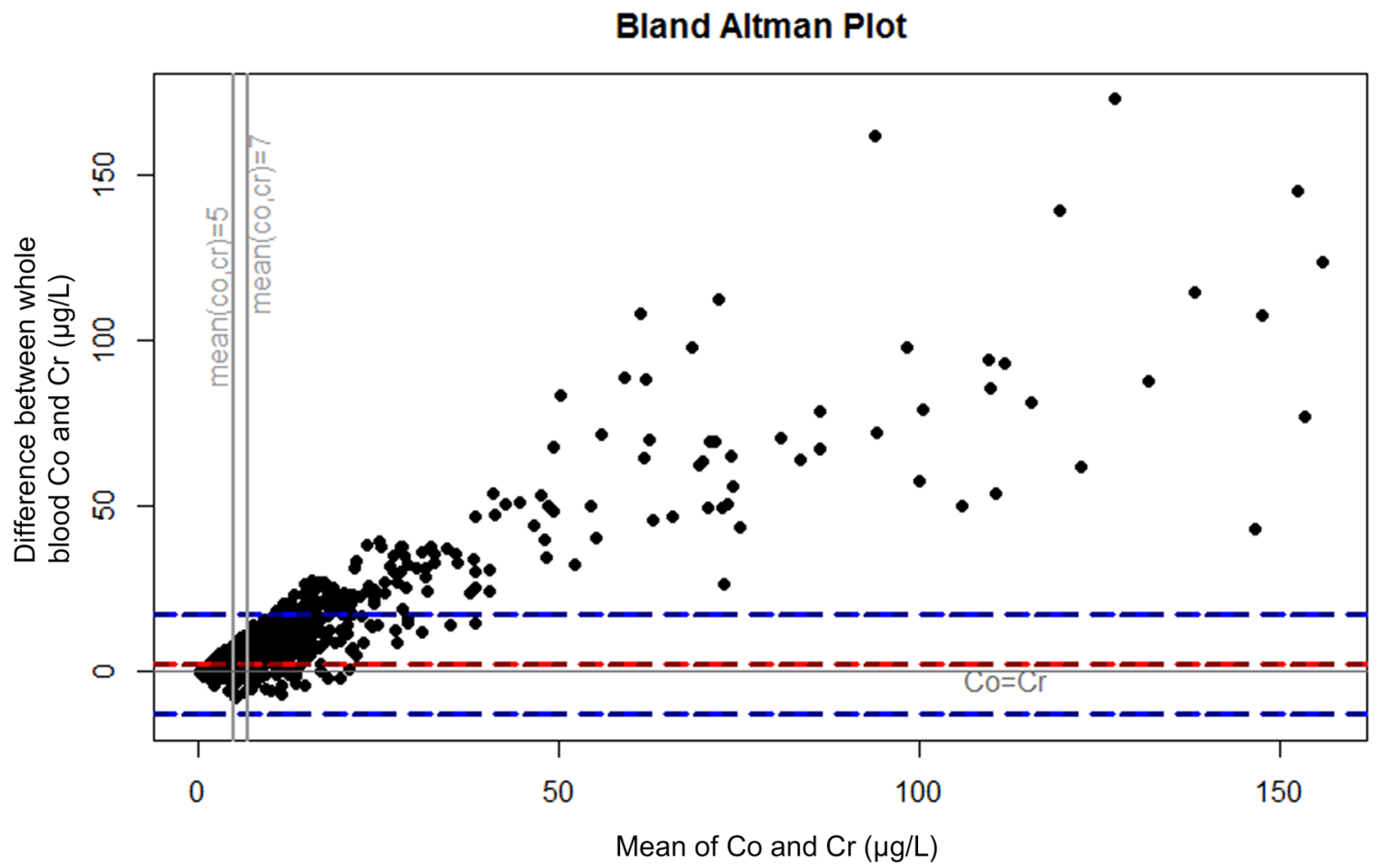

Figure 2. Bland-Altman plot representing the difference between whole blood Co and Cr in relation to the mean of whole blood $\mathrm{Co}$ and $\mathrm{Cr}(\mu \mathrm{g} / \mathrm{L})$. In the measurements below zero the whole blood $\mathrm{Cr}$ is higher than Co. The red line represents the mean difference and blue lines $95 \%$ confidence intervals. Measurements before/ without revision surgery from all patients with MoM hip replacement. Figure drawn with R (Version 3.5.1) ${ }^{21}$.

point of view, we consider our results to be very generalizable. When compared with the two largest hip arthroplasty registers (Supplement 4) Australia ${ }^{22}$ and the $\mathrm{UK}^{6}$, the distribution of MoM THA brands at our institution is similar to that of the Australian registry. Moreover, the two major THA brands in the UK registry are the two most used stemmed MoM THA implant brands at our institution. Although Adept and Cormet resurfacings 


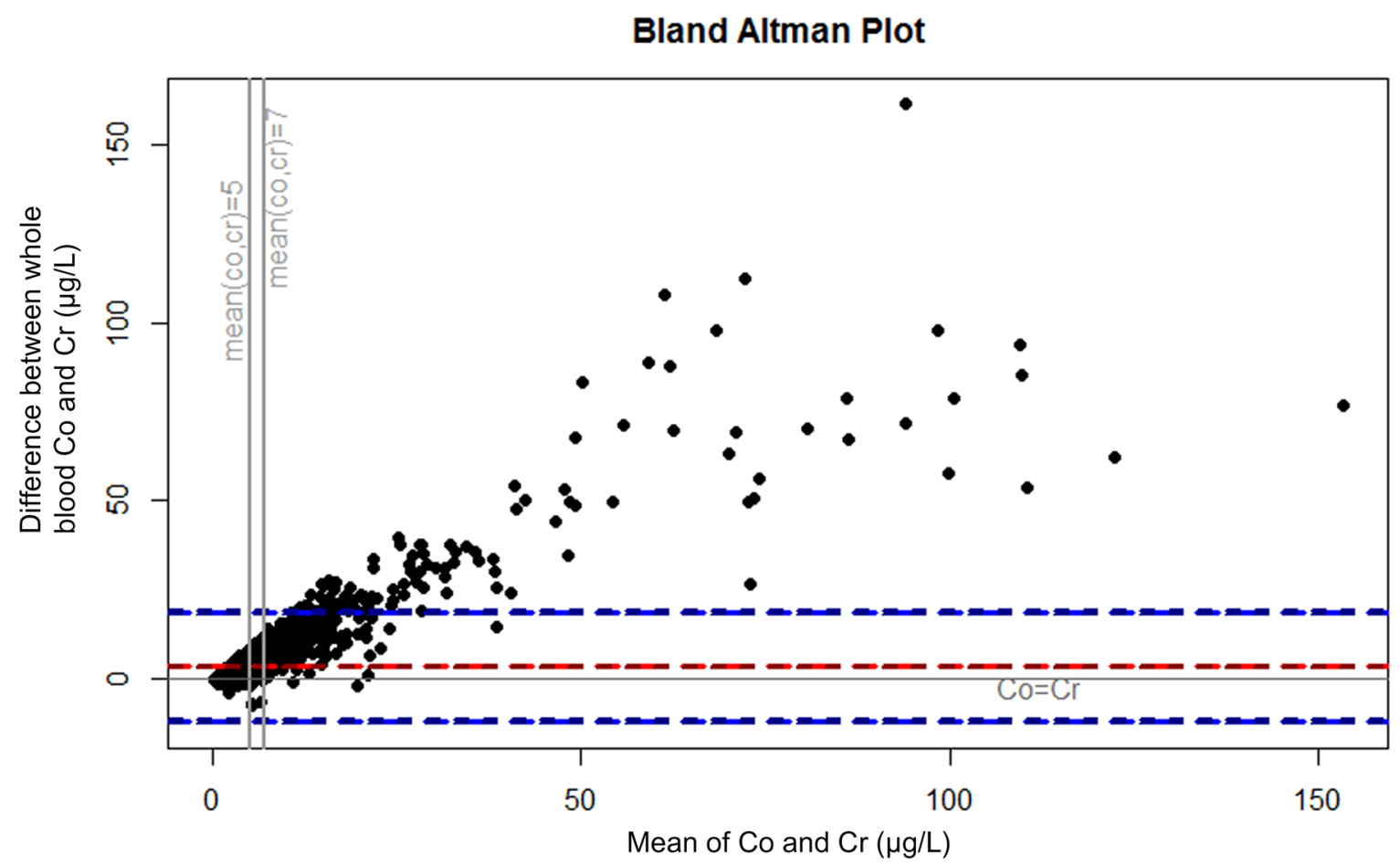

Figure 3. Bland-Altman plot representing the difference between whole blood Co and Cr in relation to the mean of whole blood Co and $\mathrm{Cr}(\mu \mathrm{g} / \mathrm{L})$ in patients with unilateral or bilateral stemmed total hip arthroplasty. In the measurements below zero the whole blood $\mathrm{Cr}$ is higher than Co. The red line represents mean difference and blue lines $95 \%$ confidence intervals. Measurements before/without revision surgery. Figure drawn with $\mathrm{R}$ (Version 3.5.1) $)^{21}$.

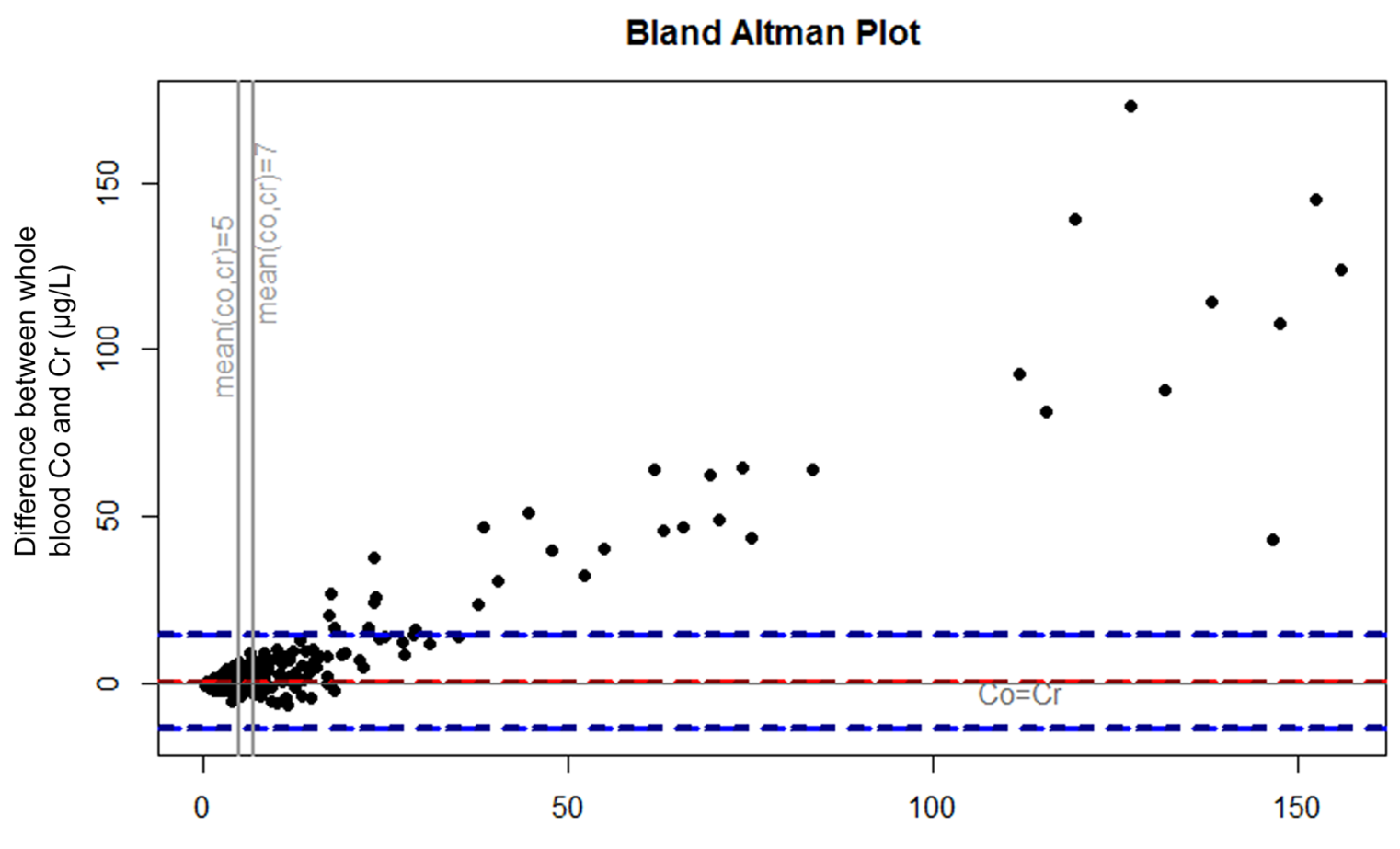

Mean of $\mathrm{Co}$ and $\mathrm{Cr}(\mu \mathrm{g} / \mathrm{L})$

Figure 4. Bland-Altman plot representing the difference between whole blood Co and Cr in relation to the mean of whole blood Co and $\mathrm{Cr}(\mu \mathrm{g} / \mathrm{L})$ in patients with unilateral or bilateral hip resurfacings. In the measurements below zero the whole blood $\mathrm{Cr}$ is higher than Co. The red line represents mean difference and blue lines $95 \%$ confidence intervals. Measurements before/without revision surgery. Figure drawn with RStudio $\mathrm{R}$ (Version 3.5.1) $)^{21}$. 
were not used at our institution, both of which were commonly used in Australia (10\% and $4 \%)$ and in UK (10\% and $10 \%$ ), the other commonly used resurfacing brands are well represented in our study group.

We did exclude measurements performed after revision from our main analyses as our previous study showed that $\mathrm{Cr}$ might remain elevated after revision surgery. We think that this exclusion is justified, as when Table 2 and Supplement 1 are compared, it can be seen that measurements after revision are more often related with independently elevated Cr. Although there are relatively many revisions among patients with MoM hip replacements, majority of patients still have well-performing implants. Thus, we think that one should aim to simplicity and cost reductions especially in follow-up of these patients, who still comprise the largest MoM patient group and will be going through multiple repeated measurements. Our current study does not take a stance on the postMoM-revision follow-up. The European consensus statement advises against routine metal ion measurements after revision as there are no effective interventions available even if the ions remain elevated after revision ${ }^{9}$. Even if some institutions wish to monitor $\mathrm{Co}$ and $\mathrm{Cr}$ after revision until they are at normal level, this comprises a relatively small patient group and the follow-up can be discontinued when $\mathrm{Co} / \mathrm{Cr}$ are at normal level, as the source of ions has been removed. Therefore, the need for cost savings is clearly smaller than in unrevised patients who may have to go through repeated $\mathrm{Co}$ and $\mathrm{Cr}$ measurements for decades. Longitudinal changes of $\mathrm{Co}$ and $\mathrm{Cr}$ were not included in this article, as it is such a vast aspect with much discussion needed about survivorship bias due to high prevalence of revisions. A separate study will be published about longitudinal changes.

Whole blood metal ion measurements are included in all major follow-up guidelines ${ }^{2-4,8,9}$. The UK MHRA and the TGA mention both $\mathrm{Co}$ and $\mathrm{Cr}^{3,8}$, whereas the FDA does not consider Cr measurements a necessity ${ }^{2}$. To date, however, no strong evidence has been presented that shows that one of these practices would be better than the other. Moreover, some institutions have omitted $\mathrm{Cr}$ due to their experience of negligible benefit ${ }^{10}$. Although MoM hip replacements are not the huge controversy they were a decade ago, it should be noted that the majority of MoM hip replacements still remain in situ. Based on the revision rates reported by UK National Joint Replacement Registry (15-year cumulative percentage of $24 \%$ for stemmed MoM THAs and $15 \%$ for resurfacings) ${ }^{6}$ and the Australian Orthopaedic Association Registry (15-year cumulative percentage revision of $29 \%$ for stemmed MoM THAs with head size $>32 \mathrm{~mm}$ and $12 \%$ for resurfacings $)^{22}$, it is likely that over one million out of the estimated 1.5 million MoM hips implanted worldwide ${ }^{7}$ still remain in situ and are under follow-up as recommended by the majority of the guidelines ${ }^{2-4,9}$. Annual follow-up for the life of the implant is recommended for high risk implant/patient groups by most guidelines ${ }^{3,4,8,9}$. However, the FDA does not recommend the metal ion testing of asymptomatic patients with no abnormal clinical or radiographic signs ${ }^{2}$. Low risk MoM implants can be followed at less frequent intervals ${ }^{8}$ or even at intervals similar to those of conventional hip replacements $s^{3,4,9}$. The follow-up of MoM hip replacements has been criticized for being neither evidence based nor cost effective ${ }^{7,11}$. Based on the savings of \$15-18 per measurement when $\mathrm{Cr}$ is omitted reported by Atrey et al. and Matharu et al. ${ }^{10,13}$, we believe that vast sums of money could be saved worldwide during the next decades by omitting Cr measurements from the routine follow-up of MoM patients, without decrease in the quality of the follow-up.

There is a large variety of cut-off values proposed for $\mathrm{Co}$ and $\mathrm{Cr}$ measurements. UK MHRA has been using blood metal ion level of $7 \mu \mathrm{g} / \mathrm{L}$ as a cut-off for indicating need for closer follow-up and cross-sectional imaging ${ }^{8}$. Their reports do not state references on which the cut-off is based on. Another commonly used cut-off of $5 \mu \mathrm{g} / \mathrm{L}$ is based on a study of 88 patients with MoM hip patients waiting for revision due to unexplained reason compared to 88 patients with well-functioning MoM hips ${ }^{12}$. That study found that $7 \mu \mathrm{g} / \mathrm{L}$ limit has insufficient sensitivity, and suggested $5 \mu \mathrm{g} / \mathrm{L}$ as blood Co/Cr limit to detect failure of MoM hip. A study comparing plasma $\mathrm{Co}$ and $\mathrm{Cr}$ concentrations to MRI findings in symptomatic patients concluded that sensitivity of $7 \mu \mathrm{g} / \mathrm{L}$ limit offers insufficient sensitivity and $\mathrm{Co} / \mathrm{Cr}$ measurements should not be used as sole screening test ${ }^{23}$. Whole blood cut-off of Co $4.5 \mu \mathrm{g} / \mathrm{L}$ has been proposed to predict increased wear ${ }^{20}$, and serum levels Co $4.0 \mu \mathrm{g} / \mathrm{L}$ and $4.6 \mu \mathrm{g} / \mathrm{L}$ for unilateral hip resurfacings to predict poor-/well-functioning of the implant, and $5.0 \mu \mathrm{g} / \mathrm{L}$ and $7.4 \mu \mathrm{g} / \mathrm{L}$ for bilaterals, respectively ${ }^{18}$. A consensus statement from US suggested $3 \mu \mathrm{g} / \mathrm{L}$ as an upper limit for low risk and $10 \mu \mathrm{g} / \mathrm{L}$ as lower limit for high risk (without specification of whole blood/plasma/serum), both of which seem to be arbitrary limits ${ }^{19}$. More recently, lower, implant specific whole blood Co cut-offs have been presented to differentiate between those with ARMD in revision or imaging and those with not ${ }^{13,24}$. There are also other suggested cut-offs not stated here. Almost every study published about Co and Cr cut-offs stresses that metal ion measurements should not be used as sole indicator of ARMD, and we do agree with them. Therefore, we included an analysis of metal ion concentrations as a continuous variable as we believe that there is no such thing as a universally optimal cut-off. Still, we wanted to include analyses with two widely used cut-offs of $5 \mu \mathrm{g} / \mathrm{L}$ and $7 \mu \mathrm{g} / \mathrm{L}$ to better demonstrate to those readers who use these cut-offs that how seldom Cr measurements provide any additional value.

Both whole blood and plasma/serum measurements are used for follow-up of MoM hip replacements, although guidelines recommend using whole blood measurements ${ }^{2,4,8}$. There are few studies about interchangeability of whole blood and plasma/serum measurements of $\mathrm{Co}$ and $\mathrm{Cr}$, all of which came into a conclusion than whole blood and plasma/serum measurements cannot be used interchangeably ${ }^{20,25-27}$. Two of these studies ${ }^{25,27}$ stated that the values are not interconvertible, meaning that plasma/serum values cannot be reliably converted to whole blood value with a conversion factor, while one ${ }^{26}$ suggested that conversion factor could be used. These studies observed higher discrepancy between plasma/serum and blood ion levels at higher concentrations ${ }^{20,25,26,28}$. The difference between plasma/serum and blood values is larger in Cr compared to Co, with higher Cr concentration in plasma/serum ${ }^{25-28}$. As the conclusions in this study are based on whole blood $\mathrm{Cr}$ concentrations being rarely independently elevated, because of tendency for relatively higher plasma/serum Cr concentration the results might be different if we had used plasma/serum measurements. We do not know how large percentage of the measurements are performed from plasma/serum worldwide.

$\mathrm{Co} / \mathrm{Cr}$ ratio has been proposed as an additional way to measure taper corrosion in MoM THAs ${ }^{16}$, and $\mathrm{Co} / \mathrm{Cr}$ ratio is reported to be higher in THAs compared to resurfacings ${ }^{29,30}$. Few studies have explored the clinical use 
of $\mathrm{Co} / \mathrm{Cr}$ ratio for detecting MRI or revision confirmed ARMD by examining receiving operating characteristic (ROC) curves, and none of them found $\mathrm{Co} / \mathrm{Cr}$ ratio to be superior compared to measuring Co alone ${ }^{13,29,31}$. We do think that it is not even relevant whether or not high $\mathrm{Co} / \mathrm{Cr}$ ratio predicts the presence of ARMD. Increasing $\mathrm{Co} / \mathrm{Cr}$ ratio describes a disproportional increase of Co compared to $\mathrm{Cr}$, which is very often the case as seen in our Figs. 2,3and4. If an institution would change their practice to measuring Co only, they would still detect the patients in which the $\mathrm{Co}$ is increasing, despite not calculating $\mathrm{Co} / \mathrm{Cr}$. Increasing $\mathrm{Co} / \mathrm{Cr}$ ratio raises concerns due to increasing Co, not because of decreasing Cr. We are currently moving from mid-term to long-term follow-up and majority of the remaining MoM hips are still performing well. If an institution wishes to use $\mathrm{Co} / \mathrm{Cr}$ ratio for pre-revision planning to estimate whether the bearing surface or the trunnion is more likely to be a problem, additional Co and Cr measurement can still be used for those few patients who are under consideration for revision surgery or with suspicion of trunnion problematics, while simplifying the follow-up of the vast majority. And it must also be noted that pre-revision $\mathrm{Co} / \mathrm{Cr}$ ratio has not been shown to reliably predict the severity of taper corrosion. Thus, it does not help the surgeon to decide beforehand, whether the stem also needs to be exchanged if it is well-fixed in pre-revision radiographs. In practice, that decision is still made perioperatively no matter how high the blood metal ion values or the $\mathrm{Co} / \mathrm{Cr}$ ratio are.

\section{Conclusion}

Our study provides robust evidence that whole blood $\mathrm{Cr}$ is very rarely elevated without whole blood Co also being elevated. As current guidelines either place equal value on $\mathrm{Co}$ and $\mathrm{Cr}$ in decision making, or even stress the importance of blood Co concentration, the authorities should consider omitting Cr measurements from their screening guidelines of MoM hip replacements. Recent studies have reported that measuring only Co would result in savings of \$15-18 per measurement. Considering the large number of patients with MoM hip replacements still in follow-up going through repeated measurements, this simple change in clinical practice could result in large cost savings.

\section{Data availability}

The datasets generated and analyzed during the current study can't be made publicly available due to containing identifiable information of our patients (the policy by our hospital district). We will be happy to provide additional analyses requested by the readers of the article, for example to be used in systematic review articles. On a reasonable request we can provide the whole blood Co and $\mathrm{Cr}$ measurement data without other clinical information (which could be combined to identify the patients).

Received: 14 November 2020; Accepted: 19 May 2021

Published online: 11 June 2021

\section{References}

1. MHRA. Medicines and Healthcare products Regulatory Agency. Medical device alert: All metal-on-metal (MoM) hip replacements (MDA/2012/036) (accessed 2021). http://www.mhra.gov.uk/home/groups/dts-bs/documents/medicaldevicealert/con155767.pdf (2012).

2. FDA. U.S. Food \& Drug Administration. Information about soft tissue imaging and metal ion testing (accessed 2021). https:// www.fda.gov/medical-devices/metal-metal-hip-implants/information-about-soft-tissue-imaging-and-metal-ion-testing (2019).

3. TGA Australian Government. Department of Health. Therapeutic Goods Administration. Metal-on-Metal hip replacement implants: Information for general practitioners, orthopaedics surgeons and other health professionals (accessed 2021). https:// www.tga.gov.au/metal-metal-hip-replacement-implants (2017).

4. SCENIHR. Scientific Committee on Emerging and Newly Identified Health Risks. Opinion on the safety of metal-on-metal joint replacements with a particular focus on hip implants (accessed 2021). September 2014. https://ec.europa.eu/health/sites/health/ files/scientific_committees/emerging/docs/scenihr_o_042.pdf (2014).

5. Cohen, D. How safe are metal-on-metal hip implants?. BMJ 344, e1410 (2012).

6. NJR. National Joint Registry for England, Wales, Northern Ireland and the Isle of Man. 16th Annual Report 2019 (accessed 2021) https://reports.njrcentre.org.uk/Portals/0/PDFdownloads/NJR\%2016th\%20Annual\%20Report\%202019.pdf.

7. Matharu, G. S., Judge, A., Pandit, H. G. \& Murray, D. W. Follow-up for patients with metal-on-metal hip replacements: Are the new MHRA recommendations justified?. BMJ 360, k566 (2018).

8. MHRA. Medicines and Healthcare products Regulatory Agency. Medical device alert: all metal-on-metal (MoM) hip replacements (MDA/2017/018) (accessed 2021). https://assets.publishing.service.gov.uk/media/5954ca1ded915d0baa00009b/MDA-2017-018_ Final.pdf.

9. Gunther, K. P. et al. Consensus statement “Current evidence on the management of metal-on-metal bearings"-April 16, 2012. Hip int. 23, 2-5 (2013).

10. Atrey, A. et al. 601 metal-on-metal total hip replacements with $36 \mathrm{~mm}$ heads a 5 minimum year follow up: Levels of ARMD remain low despite a comprehensive screening program. J. Orthop. 14, 108-114 (2016).

11. Matharu, G. S., Mellon, S. J., Murray, D. W. \& Pandit, H. G. Follow-up of metal-on-metal hip arthroplasty patients is currently not evidence based or cost effective. J. Arthroplasty.30(8), 1317-1323 (2015).

12. Hart, A. J. et al. Sensitivity and specificity of blood cobalt and chromium metal ions for predicting failure of metal-on-metal hip replacement. J. Bone Jt. Surg. Br. 93, 1308-1313 (2011).

13. Matharu, G. S. et al. The effectiveness of blood metal ions in identifying patients with unilateral Birmingham hip resurfacing and corail-pinnacle metal-on-metal hip implants at risk of adverse reactions to metal debris. J. Bone Jt. Surg. Am. 98, 617-626 (2016).

14. Depuy Orthopaedics. ASR Recall 2010 (accessed 2021). https://www.jnjmedicaldevices.com/en-US/news-events/depuy-ortho paedics-voluntarily-recalls-asrtm-hip-system-depuy.

15. AOANJRR. Australian Orthopaedic Association, National Joint Replacement Registry, Annual Report 2010 (accessed 2021 ). https://aoanjrr.sahmri.com/documents/10180/42844/Annual+Report+2010.

16. Hothi, H. S. et al. The relationship between cobalt/chromium ratios and the high prevalence of head-stem junction corrosion in metal-on-metal total hip arthroplasty. J. Arthroplasty 31, 1123-1127 (2016).

17. Lainiala, O. et al. Revision of metal-on-metal hip prostheses results in marked reduction of blood cobalt and chromium ion concentrations. Clin. Orthop. 473, 2305-2313 (2015). 
18. Van Der Straeten, C. et al. The 2012 Otto Aufranc Award: The interpretation of metal ion levels in unilateral and bilateral hip resurfacing. Clin. Orthop. 471, 377-385 (2013).

19. Kwon, Y. M. et al. Risk stratification algorithm for management of patients with metal-on-metal hip arthroplasty: Consensus statement of the American Association of Hip and Knee Surgeons, the American Academy of Orthopaedic Surgeons, and the Hip Society. J. Bone Jt. Surg. Am. 96, e4 (2014).

20. Sidaginamale, R. P. et al. Blood metal ion testing is an effectivescreening tool to identify poorly performing metal-on-metal bearing surfaces. Bone Jt. Res. 2, 84-95 (2013).

21. R Core Team. R: A Language and Environment for Statistical Computing. R Foundation for Statistical Computing. Vienna Austria. R3.5.1\$2018. https://www.r-project.org.

22. AOANJRR Australian Orthopaedic Association, National Joint Replacement Registry, Annual Report 2019 (accessed 2021). https:// aoanjrr.sahmri.com/documents/10180/668596/Hip\%2C+Knee+\%26+Shoulder+Arthroplasty/c287d2a3-22df-a3bb-37a2-91e6c 00bfcfo.

23. Malek, I. A. et al. The sensitivity, specificity and predictive values of raised plasma metal ion levels in the diagnosis of adverse reaction to metal debris in symptomatic patients with a metal-on-metal arthroplasty of the hip. J. Bone Jt. Surg. Br. 94, 1045-1050 (2012).

24. Matharu, G. S. et al. Blood metal ion thresholds to identify patients with metal-on-metal hip implants at risk of adverse reactions to metal debris: An external multicenter validation study of birmingham hip resurfacing and corail-pinnacle implants. J. Bone Jt. Surg. Am. 99, 1532-1539 (2017).

25. Malek, I. A. et al. The interchangeability of plasma and whole blood metal ion measurement in the monitoring of metal on metal hips. Arthritis 2015, 216785 (2015).

26. Smolders, J. M. et al. Metal ion interpretation in resurfacing versus conventional hip arthroplasty and in whole blood versus serum. How should we interpret metal ion data. Hip int. 21, 587-595 (2011).

27. Daniel, J., Ziaee, H., Pynsent, P. B. \& McMinn, D. J. The validity of serum levels as a surrogate measure of systemic exposure to metal ions in hip replacement. J. Bone Jt. Surg. Br. 89, 736-741 (2007).

28. Walter, L. R., Marel, E., Harbury, R. \& Wearne, J. Distribution of chromium and cobalt ions in various blood fractions after resurfacing hip arthroplasty. J. Arthroplasty 23, 814-821 (2008).

29. Laaksonen, I. et al. The cobalt/chromium ratio provides similar diagnostic value to a low cobalt threshold in predicting adverse local tissue reactions in patients with metal-on-metal hip arthroplasty. J. Arthroplasty 33, 3020-3024 (2018).

30. Ilo, K. C. et al. Does modularity of metal-on-metal hip implants increase cobalt: Chromium ratio?. Hip Int. 31, 109-114 (2021).

31. Kwon, Y. M., Tsai, T. Y., Leone, W. A. \& Liow, M. H. L. Sensitivity and specificity of metal ion levels in predicting "pseudotumors" due to taper corrosion in patients with dual taper modular total hip arthroplasty. J. Arthroplasty 32, 996-1000 (2017).

\section{Acknowledgements}

We would like to thank Ella Lehto RN, and Heli Kupari RN, Coxa Hospital for Joint Replacement, Tampere, Finland, for maintaining the study database. We thank Peter Heath, professional scientific language reviewer, for spell checking of the manuscript. This work was performed at Coxa Hospital for Joint Replacement and Faculty of Medicine and Health Technologies, Tampere University.

\section{Author contributions}

O.L.: study design, literature search, interpretation of the results, writing and revision of the manuscript, and final approval. M.K.: study design, data collection and analysis, interpretation of data, statistics, writing and revision of the manuscript, and final approval. A.R., A.E.: study design, interpretation of data and statistics, writing and revision of the manuscript, and final approval.

\section{Funding}

Our institution received funding from the research funds of our hospital district, representing public funding. The funding source had no role in data collection or manuscript preparation. We did not receive funding from any commercial party.

\section{Competing interests}

This study was supported by the competitive research funds of Pirkanmaa Hospital District, Tampere, Finland, representing governmental funding. The funding source had no role in data collection or manuscript preparation. Independently potential conflicts of interests: OL: none. MK: none, AR: none. AE: Zimmer Biomet, paid lectures; Depuy Synthes and Zimmer Biomet, institutional research support (not related to current study).

\section{Additional information}

Supplementary Information The online version contains supplementary material available at https://doi.org/ 10.1038/s41598-021-91512-9.

Correspondence and requests for materials should be addressed to O.L.

Reprints and permissions information is available at www.nature.com/reprints.

Publisher's note Springer Nature remains neutral with regard to jurisdictional claims in published maps and institutional affiliations. 
(c) (i) Open Access This article is licensed under a Creative Commons Attribution 4.0 International cc) License, which permits use, sharing, adaptation, distribution and reproduction in any medium or format, as long as you give appropriate credit to the original author(s) and the source, provide a link to the Creative Commons licence, and indicate if changes were made. The images or other third party material in this article are included in the article's Creative Commons licence, unless indicated otherwise in a credit line to the material. If material is not included in the article's Creative Commons licence and your intended use is not permitted by statutory regulation or exceeds the permitted use, you will need to obtain permission directly from the copyright holder. To view a copy of this licence, visit http://creativecommons.org/licenses/by/4.0/.

(C) The Author(s) 2021 